\title{
Letra, música e performance: uma análise cancional.
}

\section{Márlon Souza Vieira}

Mestre em Artes - UNESP. Licenciado em Música, UBM. Docente do Curso de Pós-graduação em Educação Infantil e Edução Especial - módulo de Arte Educação. UGB Ferp. Docente do Curso de Licenciatura em Música, UBM.

\section{Jovana de Almeida Vieira}

Graduada em Letras - Português/Literatura e Inglês - UGB Ferp. Especialista em Metodologia do Ensino da Língua Portuguesa - Uninter. Docente no Instituto Educacional Radeane. 


\section{Resumo}

Este artigo tem como proposta a realização de um estudo sobre o gênero "canção", a partir do modelo de análise tripartido, conforme proposto pelos autores Luiz Tatit (2003) e Cláudia Neiva Matos (2006), que desenvolveram uma abordagem teórica considerando a análise da canção não apenas a partir do eixo letra, mas também dos elementos musicais e dos processos performáticos. Com relação a este último elemento, utilizaremos as considerações de Paul Zumthor, que ressignifica o conceito de "performance" e demonstra sua importância para o processo de recepção estética. A partir desse panorama, ajuizamos como objetivo deste trabalho, a revisitação deste modelo teórico e sua posterior aplicação em forma de análise comparativa visando ao estabelecimento de um modelo de análise. Para o desenvolvimento deste caso, examinamos a música "Além do Horizonte", de Roberto Carlos e Erasmo Carlos, em quatro versões distintas, buscando demonstrar que, apesar da manutenção do eixo "letra", o resultado final, ou seja, a produção de sentido gerada pela audição, sofre graus distintos de modificação devido às mudanças nos demais eixos: música e performance. Afirmamos ainda que a ação performática se configura como elemento fundamental no processo de construção de sentido, de modo que a performance se agrega ao discurso verbal e à composição musical formando, assim, o sentido final do conjunto cancional.

Palavras- chave: canção; gênero textual; letra; música; performance

\section{Abstract}

This article has as proposal the accomplishment of a study on the song genre, from the tripartite model as proposed by the authors Luiz Tatit (2003) and Cláudia Neiva Matos (2006), who developed a theoretical approach considering the analysis of the song not only from the letter axis, but also from the musical elements and the performative processes. In relation to this last element, we will use the considerations of Paul Zumthor, which means the concept of performance and demonstrates its importance to the process of aesthetic reception. From this perspective, we propose as objective of this work, the revision of this theoretical model and its subsequent application in the form of comparative analysis aiming the establishment of a model of analysis. For the development of this case, we examined the music "Além do Horizonte", by Roberto Carlos and Erasmo Carlos, in four different versions seeking to demonstrate that, despite the maintenance of the letter axis, the result, that is, the production of sense generated by the hearing, suffers different degrees of change due to changes in the other axes: music and performance. We affirm still that performing action is configured as a fundamental element in the process of construction of sense, so that the performance is added to the verbal discourse and to the musical composition thus forming the final meaning of the ensemble. 
Keywords: song; textual genre; letter; music; performance

\section{Introdução}

Presente em todas as culturas, desde a antiguidade, a prática do canto sempre encontrou lugar nas formas pelas quais os homens constituem relações entre si e nos entendimentos de como sobrevivem. A midiatização, tão característica de nossa atualidade, permite que a canção esteja presente no cotidiano da maioria das pessoas, perpassando por momentos de comemoração, de entretenimento, de trabalho e seja comercializada pela indústria cultural.

Esse crescimento midiático proporciona ao gênero em questão ser ainda mais acessível com as facilidades advindas da tecnologia. O gênero canção é ainda pouco utilizado em salas de aula, apesar de os Parâmetros Curriculares Nacionais recomendarem a contemplação da variedade de gêneros textuais. A abordagem proposta pelo modelo tripartido, que contempla o discurso verbal, a composição musical e a performance vocal, é pouco ou nada explorada nas aulas ou livros didáticos utilizados nos ensinos fundamental e médio. Por tradição, a canção tende a ser estudada somente pelo elemento linguístico (verbal), menosprezando-se os elementos extralinguísticos musical (melodia e ritmo) e performático (voz) -, que também são fundamentais como formadores dos sentidos em conjunto.

As canções fazem parte, praticamente, da quase totalidade da população brasileira, em especial os adolescentes e jovens, que escutam-nas no seu dia a dia, seja como forma de entretenimento ou de apreciação estética. No rádio, na TV, nas lojas, nos celulares e computadores, as canções se fazem presentes em seus diversos ritmos e temáticas. Apesar disso, pouca atenção é dada a esse gênero nos anos de formação escolar.

As letras são formas textuais elaboradas com a intenção de se transmitir uma mensagem que costuma vir carregada com cunho moral, sentimental, social e/ou político. Dessa forma, podem ser utilizadas como um instrumento de dominação ideológica, firmando e fortalecendo novos valores, pensamentos e reforçando um senso comum. Portanto, faz-se necessária uma compreensão crítica das suas gradações: estrutural, lexical, sonora e artística. 
A canção é definida como uma prática humana complexa, com texto, música e performance integradas e sucedidas simultaneamente e, sem dúvida, um fenômeno difundido por todos os tempos. A proposta deste artigo é o de realizar um estudo sobre a canção que está além da relação texto e música. O papel e o significado do texto são “contaminados" pela voz performática que promove a atualização dos elementos compostos pela canção.

Escolhemos a música "Além do Horizonte", de Roberto Carlos e Erasmo Carlos, em quatro diferentes versões procurando mostrar que, embora haja permanência do eixo "letra", o resultado final, ou seja, a construção de sentido gerada pela audição sofre graus distintos de modificação devido às mudanças nos demais eixos: música e performance.

Por meio de uma pesquisa bibliográfica, dividimos este artigo em duas grandes seções. Na primeira seção procuramos fazer algumas considerações ao estudo da canção trazendo alguns aspectos próprios de sua construção e estudo em sala de aula. Já na segunda seção, analisaremos a canção Além do Horizonte, de Roberto Carlos e Erasmo Carlos. Nas considerações finais, refletimos sobre a hipótese levantada, buscando afirmar o que a análise levantou.

Diante do exposto, o objetivo da pesquisa é enfatizar a importância de estudar a canção em um modelo intersemiótico, considerando a experiência estética; demonstrar que através da canção podemos nos expressar e comunicar e conhecer a possibilidade de acesso sensorial do expectador a partir das referentes obras.

\section{Fundamentação Teórica}

\section{AS LINGUAGENS DA CANÇÃO}

A canção como gênero textual possui pressupostos que constituem um conjunto de elementos que a configuram. Matos constata que: 
[...] uma grande variedade dos pontos passíveis de focalização na análise de canções: funções e efeitos performáticos, atuação da voz e do corpo, relação da materialidade fonética/linguística com a matéria/estrutura musical, carga semântica da musicalização, organização do discurso poético, implicações socioculturais, constituição e renovação de gêneros, valores e procedimentos estéticos, aspectos do processo de recepção. Sem dúvida, os melhores resultados serão atingidos na medida em que o esforço de leitura tenda à conjunção entre os dados mais que à exploração particularizada de um deles. (MATOS, 2002, p. 142)

Dessa maneira, alguns aspectos que interagem entre o texto, a música e a emissão vocal serão abordados a seguir.

\section{A Canção como Gênero Textual}

O gênero "canção" é ainda pouco utilizado em salas de aula, apesar de os Parâmetros Curriculares Nacionais recomendarem a contemplação da variedade de gêneros textuais por considerar mais importante o contexto de uso do que o estudo da forma e do conteúdo descontextualizados. Didaticamente, utilizar a canção como facilitadora da aprendizagem é justificável por ser um recurso que causa prazer, sensações e entretenimento.

Um gênero é concebido quando ocorre a necessidade das situações de interação social, eles se moldam e se estabilizam nas atividades de comunicação humana, sendo impossível controlar ou determinar sua manifestação. Estão vinculados à vida social e cultural, contribuindo para organizar e estabelecer as realizações comunicativas do dia a dia, apresentando um alto grau de possibilidade preditiva e interpretativa das atividades humanas em qualquer contexto discursivo, como aponta Marcuschi (2003).

Em plena atualidade, surge uma variedade de novos gêneros e novas formas de comunicação, tanto na oralidade como na escrita, advindos do processo eletrônico. Ainda segundo Marcuschi, 
Esses gêneros que emergiram no último século no contexto das mais diversas mídias criam formas comunicativas próprias com certo hibridismo que desafia as relações entre oralidade e escrita e inviabiliza de forma definitiva a velha visão dicotômica ainda presente em muitos manuais de ensino de língua. Esses gêneros também permitem observar a maior integração entre os vários tipos de semioses: signos verbais, sons, imagens e formas em movimento. (MARCUSCHI, 2003, p.21)

Dentro da concepção do que é o gênero textual, Costa (2003, p.107) define a canção como "um gênero híbrido, de caráter intersemiótico". Dentro dessa perspectiva, temos como resultado um conjunto composto por três elementos - a letra, a música e a performance - o que torna a canção um gênero textual autônomo. Para Finnegan (2008), a canção é definida como uma prática humana complexa, com texto, música e performance integrados e sucedidos simultaneamente e, sem dúvida, um fenômeno difundido por todos os tempos e culturas sendo considerado um dos verdadeiros universais da vida humana.

\section{Canção e Letra}

As canções fazem parte, praticamente, da quase totalidade da população brasileira, em especial os adolescentes e os jovens, que as escutam no seu dia a dia, seja como forma de entretenimento ou de apreciação estética. No rádio, na TV, nas lojas, nos celulares e computadores as canções se fazem presentes em seus diversos ritmos e temáticas. Apesar disso, pouca atenção é dada a esse gênero nos anos de formação escolar.

As letras são formas textuais elaboradas com a intenção de se transmitir uma mensagem que costuma vir carregada com cunho moral, sentimental, social e/ou político. Para Tatit, “o plano da expressão (o significante) das linguagens estéticas é também um espaço lúdico e experimental em que o artista manobra algumas tentativas de arte sem se preocupar com o resultado." Dessa forma, podem ser utilizadas como um instrumento de dominação ideológica, firmando e fortalecendo novos valores, 
pensamentos e reforçando um senso comum. Portanto, faz-se necessária uma compreensão crítica das suas gradações: estrutural, lexical, sonora e artística.

Existe uma tradição acadêmica em estudar a canção em seu aspecto verbal, pois “A canção tem uma dimensão escrita inquestionável [...] Por isso, ela se dispõe a ser objeto de análise das disciplinas que privilegiam a matéria escrita, especialmente a literatura."(COSTA, 2002, p. 200).

Não é de se surpreender que a palavra escrita tenha com tanta frequência tido lugar central no estudo das canções - é ela que pode ser isolada para análise e transmissão [...]. Mesmo para as apresentações orais ou performances vocais dos dias de hoje, é igualmente o texto ou letra da canção que tendem a ser tratados. (FINNEGAN, 2008, p.19)

As letras de músicas, em situações variadas, contam histórias, criam personagens e enredos e podem ser construídas com recursos semelhantes ao da criação poética (há casos de poemas que foram musicados) e, apesar de permitirem essa intersecção por características provenientes de sua materialidade e por algumas formas comuns em sua produção, são distintas, pois possuem uma série de elementos que configuram dois modos diversos de expressão.

\section{Canção e Música}

Por se tratar de um gênero híbrido (lítero-musical-performático), não podemos nos limitar aos aspectos linguísticos e discursivos tão-somente, mas analisarmos o conteúdo de ritmo e melodia de uma canção. Segundo Tereza Virginia de Almeida (2008, p.316) "Trata-se não apenas de investigar os recursos que se dispõe a Literatura como disciplina para a análise da canção, mas, ainda, de perceber que, sob olhar da crítica literária, a canção expõe suas especificidades, em contraste com a escrita." Tatit (2003, p.9) ainda afirma que "Tudo fica mais claro e mais completo ao se verificar a interdependência entre a melodia e a letra da canção." 
Samba, reggae, rock, sertanejo, pagode, etc são gêneros - não textuais, mas musicais. Segundo Tatit (2003, p.7): "todas essas designações de gênero denotam a compreensão global de uma gramática. Significa que o ouvinte conseguiu integrar inúmeras unidades sonoras numa sequência com outras do mesmo paradigma”. Assim, como os gêneros textuais, há uma grande variedade de gêneros musicais que estão sujeitos à mudança pelo motivo da música ser um fato social: está presente em nossas vidas para relaxar, divertir, entreter, comemorar, entre tantas outras. A música é uma linguagem que realiza um sistema de signos próprios e podem ser combinados entre si para a criação de enunciados interagindo com um ou mais ouvintes em situação comunicativa concreta. Dessa forma, Finnegan afirma que "seria mais útil pensar não em música versus linguagem, mas nos modos complexos segundo os quais os seres humanos apresentam sua artesania vocal".

A intensidade da musicalização, isto é, da presença ativa de fatores melódicos e rítmicos no condicionamento e realização sonora da matéria linguística, determina diferentes relações entre voz e texto, as quais partem da simples enunciação [...], passam pelas formas intermediárias ou semimusicais [...] da entoação e atingem o canto, palavra plenamente musicalizada. (MATOS, 2002, p. 143)

A roupagem musical - como o ritmo, o arranjo, os efeitos sonoros - induz significados no ouvinte, que tende a "interpretar" tal conjunto sonoro como portador de uma “mensagem" que pode ser amorosa, melancólica, trágica, etc.

\section{Canção e Performance}

A performance permeia um espaço de estudos muito complexo e recente, tendo um conceito "fluido e mutante", segundo Marvin Carlson (apud SALGADO). Nos estudos linguísticos, a performance alcança importância quando permite que o foco do enunciado e de seu conteúdo se mova para os modos da enunciação discursiva. Para Dell Hymes (apud ZUMTHOR, 2014, p.35), “A performance realiza, concretiza, faz passar algo que eu reconheço, da virtualidade à atualidade." Segundo Zumthor, a 
performance é um instante único que elabora o corpo, a memória e, mais especificamente, a voz poética, no ato das transmissões orais. A voz que lê, recita ou canta, age com determinadas limitações, mas a performance envolve, ao mesmo tempo, conhecimento, inteligência, sensibilidade, nervos, músculos, respiração. Ruth Finnegan (2008) considera que a canção e a poesia oral devem ser entendidas como performance, e não como "texto", ou seja, ela está inserida num processo de construção contínua, dando-lhe singularidade a cada nova performance.

No Brasil, estudos recentes têm sido realizados por pesquisadores, dentre eles, Luiz Tatit, em que demonstram o entrelaçamento da palavra cantada e da música, visto que as duas são indissociáveis, de forma que a palavra cantada sozinha não possui o mesmo vigor, ou o mesmo sentido, ou o mesmo impacto quando aliado a uma voz, ou a uma melodia, especificamente.

O cancionista é um gesticulador sinuoso com uma perícia intuitiva muitas vezes metaforizada com a figura do malandro, do apaixonado, do gozador, do oportunista, do lírico, mas sempre um gesticulador que manobra sua oralidade, e cativa, melodicamente, a confiança do ouvinte. (TATIT, 2002, p. 9)

Por isso, a necessidade de uma análise que perceba a palavra cantada e música associadas.

\section{ALÉM DO HORIZONTE: LETRA, VERSÕES E ANÁLISE.}

Apesar de serem amigos desde 1958, os compositores Roberto Carlos e Erasmo Carlos potencializaram seus talentos, de modo conexo, somente alguns anos depois:

Aspirantes ao sucesso, já com nome razoavelmente conhecido, Roberto e Erasmo, amigos desde 1958, só descobriram em 1963 que podiam se completar musicalmente, por ser o primeiro bom de 
melodia e o segundo bom de letra, embora fossem ambos competentes nos dois quesitos. (SEVERIANO, 2013, p.398)

Lançada originalmente no álbum "Roberto Carlos", em 1975, pelo próprio Roberto Carlos, três anos mais tarde, em 1978, teve também sua versão gravada por Nara Leão. Uma nova gravação ocorre em 1980 em que Tim Maia é convidado pelo outro compositor da canção - Erasmo Carlos - para fazer um dueto em seu LP "Erasmo Carlos convida..." E, mais recente, no ano de 2005, em uma nova releitura, o grupo J Quest, em seu quinto álbum com título “Até onde vai”. Há outras regravações da canção, porém para esta análise, nos atentaremos somente a estas, com a letra da primeira versão dos compositores.

Além do Horizonte
(Roberto Carlos/Erasmo Carlos)

Além do horizonte deve ter

Algum lugar bonito pra viver em paz

Onde eu possa encontrar a natureza

Alegria e felicidade com certeza

Lá nesse lugar o amanhecer é lindo

Com flores festejando mais um dia que vem vindo

Onde a gente pode se deitar no campo

Se amar na relva escutando o canto dos pássaros

Aproveitar a tarde sem pensar na vida

Andar despreocupado sem saber a hora de voltar

Bronzear o corpo todo sem censura

Gozar a liberdade de uma vida sem frescura

Se você não vem comigo

Tudo isso vai ficar

No horizonte esperando por nós dois 
Se você não vem comigo

Nada disso tem valor

De que vale o paraíso sem amor

Além do horizonte existe um lugar

Bonito e tranquilo pra gente se amar

Laralaralaralala...

O elemento "letra" da canção apresenta um motivo recorrente nas linguagens "poéticas" e "cancionais": o tema da utopia e forma de futuro a ser construído. O "horizonte" a ser buscado é uma metáfora muito usada nos discursos de insatisfação ou incompletude, no qual o eu (aqui, "eu cancional") manifesta o desejo de realizar algo que irá transformar sua atual condição. Daí que o horizonte funciona como um tipo de lugar em que o presente incompleto é substituído pela realização futura.

$\mathrm{O}$ eu manifesta para o ser amado o desejo de ir à busca de um lugar “melhor”. As características que justificam esse julgamento são encontradas na "paz", na natureza e na felicidade que tais elementos podem gerar para o "eu" e sua amada.

Há um conjunto de frases-feitas e lugar-comum sobre o encanto da amada e sobre a felicidade do futuro relacionamento entre ambos - o eu-lírico deseja o paraíso desde que a amada esteja com ele, de outra forma, esse paraíso não vale nada. Essa visão de paraíso é bem humanizada - o eu-lírico precisa da mulher amada - há uma idealização do amor: "Se você não vem comigo/ Tudo isso vai ficar/ No horizonte esperando por nós dois/ Se você não vem comigo/ Nada disso tem valor/ De que vale o paraíso sem amor".

Daí podemos dizer que em sua primeira parte, os temas e tópicos do Arcadismo estão presentes na canção de Roberto Carlos e Erasmo: "Além do horizonte deve ter/ Algum lugar bonito pra viver em paz/ Onde eu possa encontrar a natureza/ Alegria e felicidade com certeza." O locus amoenus, o carpe diem e o fugere urbem podem ser percebidos nos versos: "Lá nesse lugar o amanhecer é lindo/ Com flores festejando mais um dia que vem vindo/ Onde a gente pode se deitar no campo/ Se amar na relva 
escutando o canto dos pássaros/ Aproveitar a tarde sem pensar na vida/ Andar despreocupado sem saber a hora de voltar".

O Arcadismo surge no Brasil na segunda metade do século XIX. Essa escola caracteriza-se pelo bucolismo e pastoralismo. Além disso, abrange o culto à natureza, a celebração da vida campestre, a construção racional do poema, o controle sobre a emoção e a imaginação, valorizando a linguagem simples, clara e com elegância natural.

Em resumo, a letra da canção é a manifestação ponderada de um desejo de mudança. O "eu cancional” busca convencer o ser amado de que ambos deveriam ir à busca da realização desse desejo, alegando motivos simples, racionais, pautados por um ideal de vida "ameno" e "livre".

De forma geral, Matos aponta que o texto e a música podem moldar-se em função de sintaxe e significação, fazendo com que funções psíquicas de percepção intelectual e impressão afetiva sejam ativadas. Entretanto, esses modos de adequação também podem ser desfigurados: o contato entre a letra e a interpretação e o esquema rítmico-melódico permitem a interação por superposição, coincidência e convergência ou por contraste. Dito isso, veremos a seguir esses processos nas versões analisadas.

\section{Versão Roberto Carlos (1975)}

É na década de 60 que Roberto Carlos muda seu repertório para o rock, embora tenha iniciado sua carreira sob influência da bossa nova e samba-canção. A partir da década de 70, remodela seu repertório de rock, tornando-se um compositor e cantor basicamente romântico.

$\mathrm{Na}$ versão interpretada pelo próprio compositor, o gênero musical se aproxima do pop rock. A constância da "levada" determina um padrão prazeroso: o paraíso é o plano de fundo perfeito para estar com a amada.

As divisões sintáticas, silábicas e rítmicas se relacionam e as emoções climáticas são exteriorizadas de forma convergente como nos assinala Matos.

\section{Versão Nara Leão (1978)}


Ainda que Nara Leão não tivesse composto as canções que interpretava, ela tornava toda música que cantava como algo íntimo e de suma importância. Nessa época, a qualidade da música composta por Roberto Carlos e Erasmo era ainda bastante criticada e considerada inferior à Música Popular Brasileira (MPB). Entretanto, Nara grava seu LP “Que tudo vá pro inferno” contendo apenas músicas de Roberto Carlos e Erasmo Carlos, rompendo a barreira de preconceito que havia em relação aos dois compositores. Nara não se preocupava em representar um estilo musical, cantava músicas que considerava de boa qualidade, independente da opinião de outras pessoas.

Nesta versão, o gênero se aproxima do samba. Tal como na primeira versão, o esquema de ritmo e melodia somado à letra e à interpretação, percebemos a coincidência nessa interação. No arranjo é utilizado um sintetizador que imita o assobiar humano, numa tentativa de dar o tom amoroso e, ao mesmo tempo, um tom de sossego e acolhimento ao lugar chamado "além do horizonte".

\section{Versão Tim Maia e Erasmo Carlos (1980)}

Tim Maia, ao retornar para o Brasil, traz em sua bagagem a influência da Soul Music - uma condução híbrida do Rhythm and Blues e do Gospel norte-americano modelo referendado pela música dos negros tendo o auge de sua criatividade na década de 1960. Nesse contexto, esta regravação nos propicia uma interpretação mais atraente, padrão estabelecido, principalmente, pelo groove $e^{1}$ do baixo e pelo vocal silábico do cantor principal - ação típica do jazz norte-americano.

Segundo Matos (2002), é a entoação que valoriza o texto, ao mesmo tempo em que aguça os fatores psicofísicos da língua falada. A atmosfera é de festa, de dança, entretanto, a condição para que esse paraíso se apresente em tom festivo é a presença da amada, tanto que, a incerteza dela não estar, no verso "se você não vem comigo" há uma

\footnotetext{
${ }^{1}$ De acordo com o New Dictionary of Jazz, na esfera do jazz, este termo pode ser entendido como um padrão rítmico que se repete. Entretanto, alguns estudiosos definem groove como uma espécie de senso particular de algo que é sustentado de forma distinta, regular e atraente, mas ordenado, agindo de forma a atrair o ouvinte.
}

(The New Grove Dictionary of Jazz. Second Edition. Volume 2. p.100) 
mudança de intensidade na voz do intérprete, o tom fica mais grave comprovando que o paraíso não tem valor sem a amada, isto é, há uma superposição entre os eixos da canção: o esquema entre ritmo e melodia, letra e interpretação, contribuem para um efeito significativo de valor ou não dado ao paraíso.

\section{Versão Jota Quest (2005)}

Uma das bandas brasileiras que mais colecionaram sucessos nas últimas décadas é a banda mineira Jota Quest.

Em particular, nessa regravação, percebemos que a canção é iniciada pelo refrão - um recurso moderno para que a canção fique "contaminada" na mente para ser mais veiculada e, consequentemente, para obtenção de mais lucro para a indústria fonográfica.

Nesta última versão, o gênero musical proposto é o rock. O ritmo é particularmente significante para a música. Associado à rebeldia e ao ímpeto juvenil, nesta versão podemos perceber uma jovialidade trazida à letra por meio do revestimento musical, ou seja, há um contraste. Mistura as intenções da gravação em dueto de Tim Maia e Erasmo Carlos e demonstra uma forma de se declarar, de expor os sentimentos, que podemos classificar como uma vivência do presente: "o aqui e o agora"; ao contrário das versões anteriores, em que ir para "além do horizonte" exige uma condição e, se aceita, será para o futuro.

\section{Considerações Finais}

A análise comparativa procurou reconhecer o entrelaçamento da letra, música e performance de uma canção. Elas são indissociáveis, pois, sozinhas não contemplam o mesmo sentido, ou seja, o efeito performático atrelado à letra e à estrutura musical da canção e também fatores sociais e culturais são resultantes no processo de recepção do ouvinte. Desse modo, pode-se afirmar que esse gênero híbrido, isto é, lítero-musicalperformático, amplia os elementos linguísticos e discursivos, da mesma forma, em que 
os processos específicos musicais como ritmo, harmonia e melodia colaboram para um alinhamento entre a melodia e a letra da canção.”

Afirmamos assim que a ação performática se apresenta como componente essencial no processo de constituição de acepção, de modo que a performance se ajunta ao discurso verbal e à composição musical formando, assim, o sentido resultante do conjunto cancional.

\section{Referências}

ALMEIDA, Tereza Virginia de. O corpo do som: notas sobre a canção. In: MATOS, Cláudia Neiva.; TRAVASSOS, Elizabeth.; MEDEIROS, Fernanda Teixeira de (orgs). Palavra cantada: ensaios sobre poesia, música e voz. p. 316- 325. Rio de Janeiro: 7Letras, 2008.

COSTA, Nelson Barros da. As letras e a letra: o gênero canção na mídia literária. In: DIONÍSIO, Angela Paiva (org). Gêneros textuais e ensino. Rio de Janeiro: Lucerna, 2002.

FINNEGAN, Ruth. O que vem primeiro: o texto, a música ou a performance? In: MATOS, Cláudia Neiva.; TRAVASSOS, Elizabeth.; MEDEIROS, Fernanda Teixeira de (orgs.). Palavra cantada: ensaios sobre poesia, música e voz. p. 15- 40. Rio de Janeiro: 7Letras, 2008.

MARCUSCHI, Luiz Antônio. Gêneros textuais: definição e funcionalidade. In: DIONÍSIO, Angela Paiva (org.). Gêneros textuais e ensino. Rio de Janeiro: Lucerna, 2002.

MATOS, Claudia Neiva de. Anotações para um estudo da palavra cantada. In: Fronteiras do literário. REIS, Lívia de \& PARAQUETT, Márcia (org).p.133-146 Niterói: EdUFF, 2002.

Cláudia Neiva.; TRAVASSOS, Elizabeth.; MEDEIROS, Fernanda Teixeira

de (orgs.). Palavra cantada: ensaios sobre poesia, música e voz. Rio de Janeiro: 7Letras, 2008. 
, Cláudia Neiva. Todos entoam: os cancionistas e seus parceiros. Revista do Instituto de Estudos Brasileiros, n 61, ago. 2015. p.223-229. Disponível em:< http://www.scielo.br/pdf/rieb/n61/0020-3874-rieb-61-0223.pdf> Acesso em: 24 out. 2017.

PETILLO, Alexandre. et al. Curtindo música brasileira. Rio Grande do Sul: Belas Letras, 2013.

SALGADO, T. B. Introdução crítica aos Estudos da Perfomance. n. 24, dez.2012 p. 327-329. São Paulo, Online: Galaxia Disponível em:

<https://revistas.pucsp.br/index.php/galaxia/article/download/12949/9424> Acesso em: 2 set. 2017.

SEVERIANO, Jairo. Uma história da música popular brasileira: das origens à modernidade. 3. ed. São Paulo: Editora 34, 2013.

TATIT, Luiz. Elementos para a análise da canção popular. Cadernos de Semiótica Aplicada, v.1, n.2, dezembro de 2003.

, Luiz. O Cancionista. 2. ed. São Paulo: Editora da Universidade de São Paulo, 2002.

ZUMTHOR, Paul. Performance, recepção, leitura. 1. ed. São Paulo: Cosac Naify, 2014. 